\section{Analisa Kekasaran Permukaan Titanium Grade 2 pada Proses Frais}

\section{Analysis of Titanium Grade 2 Surface Roughness on Milling Process}

\author{
Am. Mufarrih¹, Moh. Nasir Hariyanto', Nanang Qosim ${ }^{1}$ \\ 1Jurusan Teknik Mesin, Politeknik Negeri Malang, Malang, Indonesia \\ e-mail: ${ }^{1}$ mufarrih@polinema.ac.id, ${ }^{2}$ moh.nasir@polinema.ac.id, \\ 3nanang.qsm@polinema.ac.id
}

\begin{abstract}
Abstrak
Titanium Grade 2 termasuk jenis bahan yang sering dipergunakan di industri, utamanya pada bahan untuk implan biomedis. Titanium Grade 2 mempunyai sifat perbandingan kekakuan terhadap berat yang baik, tahan terhadap korosi dan memiliki sifat biokompatibel yang baik di dalam tubuh. Namun memiliki konduktifitas panas yang rendah, sehingga perlu memilih perameter pemesinan yang tepat untuk menghasilkan nilai kekasaran permukaan yang baik. Penelitian ini bertujuan untuk mengetahui karakteristik Titanium Grade 2 yaitu kekasaran permukaan hasil pemesinan frais. Desain penelitian menggunakan metode Taguchi L9, dengan 2 faktor dan 3 level. Parameter pemesinan yang digunakan ialah putaran spindel 500; 700; $900 \mathrm{rpm}$ dan kecepatan pemakanan 25; 50; $75 \mathrm{~mm} /$ menit. Variabel respon yang diteliti ialah kekasaran permukaan. Proses frais dilakukan menggunakan Mesin CNC Dahlih. Kekasaran permukaan diukur menggunakan Mitutoyo surface roughess tester. Analisis data menggunakan analisis ANOVA. Hasil penelitian menunjukan bahwa ada pengaruh variasi parameter pemesinan terhadap respon kekasaran permukaan. Variabel putaran spindel mempunyai $p$-value sebesar 0,039 dan variabel gerak makan memiliki $p$-value sebesar 0,025. Hal ini menunjukkan bahwa kedua variabel bebas tersebut memiliki pengaruh yang signifikan terhadap respon kekasaran permukaan. Kekasaran permukaan terendah dapat dicapai dengan pengaturan putaran spindel sebesar $700 \mathrm{rpm}$ dan kecepatan pemakanan sebesar $25 \mathrm{~mm} /$ menit.
\end{abstract}

Kata kunci: titanium grade 2, kekasaran permukaan, frais, anova

\begin{abstract}
Titanium Grade 2 is a metal that is widely used in industry, mainly in materials for biomedical implants. Titanium Grade 2 has good stiffness to weight ratio properties, is resistant to corrosion and has good biocompatible properties in the body. However, it has low heat conductivity, so it is necessary to choose the right machining parameter to produce a good surface roughness value. This study aims to determine the characteristics of Titanium Grade 2, namely the surface roughness of milling machining results. The research design uses the Taguchi $L_{9}$ method, with 2 factors and 3 levels. The machining parameters used are spindle speed 500; 700; $900 \mathrm{rpm}$ and feeding speed 25; 50; $75 \mathrm{~mm} /$ minute. The response variable studied was surface roughness. The milling process is carried out using a Dahlih CNC Machine. Surface roughness was measured using Mitutoyo surface roughess tester. Data analysis using ANOVA analysis. The results showed that there are effects of variations in machining parameters on the response
\end{abstract}


Jurnal Pendidikan Teknik Mesin Undiksha

Vol. 8 No.2, Agustus 2020

p-ISSN: 2614-1876, e-ISSN: 2614-1884

of surface roughness. The spindle speed variable has a p-value of 0.039 and the feeding variable has a pvalue of 0.025. This shows that the two independent variables have a significant influence on the response of surface roughness. The lowest surface roughness can be achieved by adjusting the spindle speed at $700 \mathrm{rpm}$ and feeding speed at $25 \mathrm{~mm} / \mathrm{min}$.

Keywords : titanium grade 2, surface roughness, milling, anova

\section{PENDAHULUAN}

Penelitian tentang karakterisasi material baru terus dilakukan oleh berbagai kalangan. Titanium merupakan bahan yang sangat populer penggunaannya di masa ini. Penggunaan titanium mencakup berbagai sektor industri biomedis, penerbangan, elektronik serta produkproduk berukuran mikro (Bruce, 2013). Titanium juga termasuk bahan logam yang banyak dimanfaatkan dalam kehidupan manusia, seperti perhiasan, alat elekronik, alat kedokteran dan produk lain yang memerlukan kekuatan bahan tinggi. Paduan titanium telah menjadi bahan yang sangat diperlukan dalam industri dirgantara karena kekuatan dan ketahanannya yang sangat baik terhadap korosi dan suhu tinggi (Shucai, Chunsheng, \& Minli, 2019).

Penggunaan piranti implan berbasis biomaterial titanium cukup luas diaplikasikan pada bedah ortopedi dan kedokteran gigi. Titanium paduan maupun murni mempunyai sifatsifat yang memenuhi syarat sebagai bahan implant biomedis. Sifat-sifat tersebut merupakan keunggulan titanium dibandingkan jenis logam yang lain. Titanium paduan maupun murni mempunyai sifat biomekanik dan biokompatibilitas yang lebih unggul dibandingkan logam lain. Secara biologi titanium bersifat inert serta mempunyai ketahanan korosi yang sangat tinggi, hal ini karena titanium secara spontan mampu membentuk lapisan $\mathrm{TiO}_{2}$ di permukaannya (Oshida, 2012). Titanium termasuk logam transisi yang bobotnya ringan, berwarna putih berkilau, metalik dan keperakan. Keunggulan sifat titanium antara lain memiliki perbandingan antara kekuatan dan berat yang baik pada suhu tinggi, bersifat tahan patah dan tahan korosi pada temperatur tinggi. Titanium memiliki bobot $60 \%$ lebih berat dari aluminium tetapi memiliki kekuatan dua kali lebih besar dari alumunium. (Thepsonthi \& Özel, 2012). Keunggulan-keunggulan ini mendasari titanium lebih terpilih dikembangkan sebagai bahan implan dari pada jenis logam lainnya.

Selain harus terbebas dari unsur yang bersifat sitotoksik, kinerja implan juga dilihat dari mekanisme interaksi atau hubungan antara bahan implan dengan jaringan-jaringan di sekitarnya. hubungan awal antara bahan implan dengan lingkungan biologis, biasanya dipengaruhi oleh karakteristik permukaan yang berpengaruh terhadap kuantitas dan kualitas adesi sel pada permukaan produk implant, sehingga jaringan di sekitar implan dapat berkembang dengan baik (Wennerberg \& Albrektsson, 2009). Mekanisme hubungan ini terjadi di permukaan implan dengan sel hidup di dalam tubuh manusia. Beberapa hasil riset yang mengamati hubungan antar muka antara implan dengan sel hidup di sekitarnya dapat diketahui bahwa topografi, kekasaran permukaan, komposisi kimia, energi permukaan, dan lapisan oksida pada permukaan bahan implan sangat mempengaruhi kinerja implan di dalam sel tubuh agar terjadi oseointegrasi, sehingga permukaan bahan implan harus mempunyai sifat biokompatibel dan bioaktif (Tapiero, Townsend, \& Tew, 2003).

Perkembangan riset yang begitu pesat telah banyak dilakukan yang berfokus pada rekayasa permukaan implan berbasis biomaterial titanium murni maupun paduannya. Selain itu kualitas permukaan adalah karakteristik kinerja yang sangat signifikan dalam proses pemesinan. Kekasaran permukaan merupakan indikator kualitas kritis untuk kualitas permukaan, serta menjadi parameter paling penting untuk mengukur kualitas permukaan suatu produk pemesinan (Mufarrih, Istiqlaliyah, \& Ilha, 2019). Kekasaran permukaan mampu mempengaruhi fungsi suatu produk seperti gesekan permukaan, perpindahan panas, kemampuan penyebaran pelumasan dan pelapisan (Bagno \& Di Bello, 2004). Machinability 
atau mampu mesin suatu material ditentukan oleh beberapa kriteria seperti umur pahat, keausan pahat, gaya potong, temperatur potong, kondisi permukaan, dan ketinggian bur (Davim, 2011). Menurut Ganguli (Ganguli \& Kapoor, 2016) titanium merupakan material yang sulit untuk difrais, hal ini disebabkan karena konduktivitas panas bahan yang kurang baik sehingga saat proses pemesinan pada suhu tinggi menyebabkan terjadinya deformasi plastis pada pahat serta peningkatan reaktivitas kimia yang dihasilkan di zona pemotongan.

Nithayanandam, dkk (Nithyanandam, Das, \& Palanikumar, 2015) telah melakukan riset untuk melihat pengaruh parameter pemotongan proses machining terhadap kualitas kekasaran permukaan titanium dengan menggunakan pahat jenis carbide. Riset ini juga bertujuan untuk mengobservasi parameter yang paling optimal untuk menghasilkan kualitas kekasaran permukaan yang baik. Dapat disimpulkan bahwa laju pemakanan merupakan parameter yang paling dominan terhadap kualitas kekasaran permukaan, diikuti oleh kecepatan potong. Dibandingkan dua parameter ini, kedalaman pemotongan menunjukkan efek yang tidak terlalu signifikan terhadap kekasaran permukaan.

Penelitian ini menggunakan Titanium Grade 2 sebagai benda kerja dan menganalisa respon kekasaran permukaan pada proses frais dengan memvariasikan parameter proses pengefraisan yaitu kecepatan spindel dan kecepatan pemakanan.

\section{METODE}

Penelitian yang dilakukan termasuk jenis riset eksperimental, yang mempunyai tujuan untuk mengetahui interaksi sebab akibat antar variabel dengan memvariasikan parameter prosesnya. Seting parameter proses mesin frais CNC disesuaikan dengan kemapuan mesin serta merujuk penelitian terdahulu. Alat, bahan, rancangan percobaan serta analisis data dapat dijelaskan sebgai berikut.

\section{Alat dan bahan}

Mesin yang digunakan dalam penelitian ini ialah mesin frais CNC Dahlih. Pahat yang digunakan adalah end mill HSS diameter $17 \mathrm{~mm}$. Mesin CNC Dahlih ditunjukkan pada Gambar 1. Titanium grade 2 berdiameter $16 \mathrm{~mm}$ panjang $40 \mathrm{~mm}$ digunakan dalam penelitian ini. Titanium grade 2 ini memiliki tensile strength sebesar $358 \mathrm{Mpa}$, yield strength sebesar 285 Mpa dan elongation sebesar 33\%. Proses pengefraisan dilakukan dengan pemesinan kering tanpa cairan pendingin. Nilai kekasaran permukaan benda kerja hasil pengefraisan diukur menggunakan Mitutoyo Surftest Sj-210.

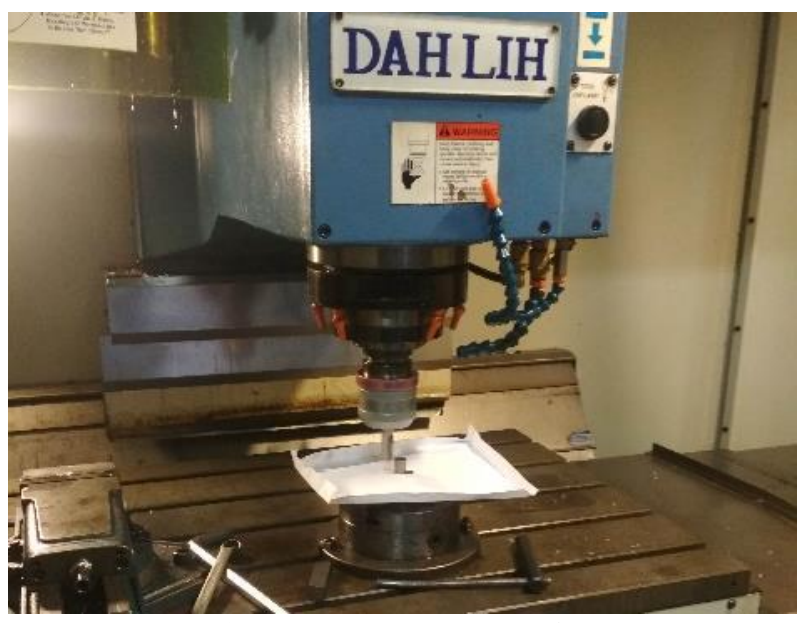

Gambar 1. Proses Pengefraisan 
Rancangan Percobaan

Seting parameter proses mesin frais CNC menyesuaikan dengan kemampuan mesin serta merujuk dari penelitian terdahulu. Tabel 1 menunjukkan level-level dari kecepatan spindel dan kecepatan pemakanan yang digunakan pada penelitian ini.

Tabel 1. Parameter proses dan level

\begin{tabular}{ccc}
\hline & \multicolumn{2}{c}{ Parameter Proses } \\
\cline { 2 - 3 } & $\begin{array}{c}\text { Kecepatan spindel } \\
(\mathbf{n})\end{array}$ & $\begin{array}{c}\text { Kecepatan pemakanan } \\
\left(\mathbf{V}_{\mathbf{f}}\right)\end{array}$ \\
\hline Satuan & $(\mathrm{rpm})$ & $(\mathrm{mm} / \mathrm{min})$ \\
Level 1 & 500 & 25 \\
Level 2 & 700 & 50 \\
Level 3 & 900 & 75 \\
\hline
\end{tabular}

Pengaturan parameter proses menggunakan metode Taguchi orthogonal array L 9 . Metode Taguchi digunakan untuk mempelajari variabel dan interaksinya yang mampu dilakukan dengan menggunakan percobaan dengan jumlah kecil (Soepangkat, Pramujati, Effendi, Norcahyo, \& Mufarrih, 2019). Rancangan percobaan ditunjukkan pada Tabel 2.

\begin{tabular}{cc}
\multicolumn{2}{c}{ Tabel 2. Rancangan percobaan } \\
\hline \multicolumn{2}{c}{ Parameter Proses } \\
\hline $\mathbf{n ~ ( r p m )}$ & $\mathbf{V}_{\mathbf{f}} \mathbf{( \mathbf { m m } / \mathbf { m i n } )}$ \\
\hline 500 & 25 \\
500 & 50 \\
500 & 75 \\
700 & 25 \\
700 & 50 \\
700 & 75 \\
900 & 25 \\
900 & 50 \\
900 & 75
\end{tabular}

\section{HASIL DAN PEMBAHASAN}

Kekasaran permukaan Titanium grade 2 ini diukur pada tiga area permukaan menggunakan Mitutoyo surface roughess tester, kemudian hasilnya dirata-rata untuk memperoleh nilai kekasaran permukaan rata-rata tiap spesimen. Tabel 3 menunjukkan hasil pengukuran kekasaran permukaan.

Tabel 3. Pengukuran kekasaran permukaan

\begin{tabular}{cccccc}
\hline \multicolumn{2}{c}{ Parameter Proses } & \multicolumn{4}{c}{ Kekasaran Permukaan $(\boldsymbol{\mu m})$} \\
\hline $\mathbf{n}(\mathbf{r p m})$ & $\begin{array}{c}\mathbf{V}_{\mathbf{f}} \\
(\mathbf{m m} / \mathbf{m i n})\end{array}$ & & & & \\
\hline & & KP 1 & KP 2 & KP 3 & KP Rata-rata \\
\hline 500 & 25 & 0,565 & 0,565 & 0,565 & 0,565 \\
500 & 50 & 0,651 & 0,646 & 0,632 & 0,643 \\
500 & 75 & 1,253 & 1,242 & 1,231 & 1,242 \\
700 & 25 & 0,432 & 0,436 & 0,428 & 0,432 \\
700 & 50 & 0,512 & 0,512 & 0,512 & 0,512 \\
700 & 75 & 0,772 & 0,768 & 0,797 & 0,779
\end{tabular}




\begin{tabular}{llllll}
900 & 25 & 0,955 & 0,965 & 0,954 & 0,958 \\
900 & 50 & 0,824 & 0,823 & 0,825 & 0,824 \\
900 & 75 & 1,184 & 1,211 & 1,181 & 1,192 \\
\hline
\end{tabular}

Grafik nilai kekasaran permukaan ditunjukkan Gambar 2.

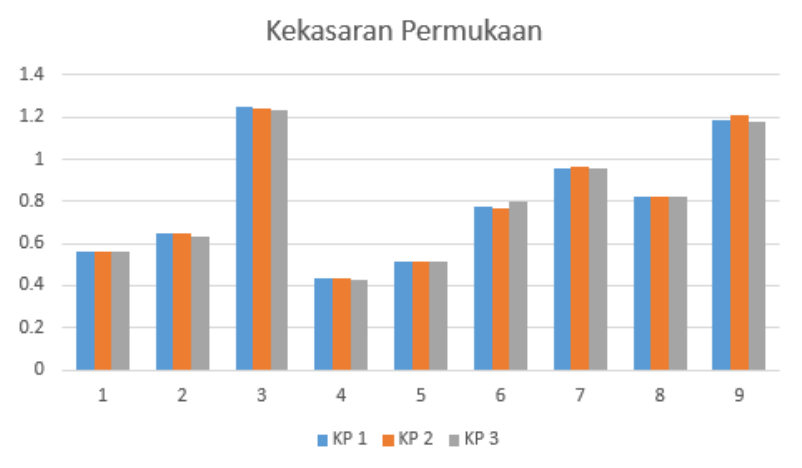

Gambar 2. Nilai Kekasaran Permukaan

Berdasarkan Gambar 2, dapat diketahui bahwa rentang nilai kekasaran permukaan dari tiga area yang diukur untuk setiap spesimen tidak jauh berbeda. Hal ini menunjukkan bahwa proses pengefraisan sudah dilakukan dengan baik.

Analisis Parameter Proses terhadap Kekasaran Permukaan

Untuk mengetahui apakah kecepatan spindel dan kecepatan pemakanan mempunyai pengaruh terhadap nilai kekasaran permukaan benda kerja hasil pengefraisan material Titanium grade 2, maka dilakukan analisis ANOVA (Analysis of variance). Syarat ANOVA dapat dilakukan adalah jika residual memenuhi tiga asumsi: identik, independen dan berdistribusi normal.

Uji asumsi identik

Asumsi identik dapat terpenuhi jika residual tidak membentuk suatu pola tertentu da tersebar secara acak disekitar harga nol. Hasil uji asumsi identik ditunjukkan pada Gambar 3. berikut.

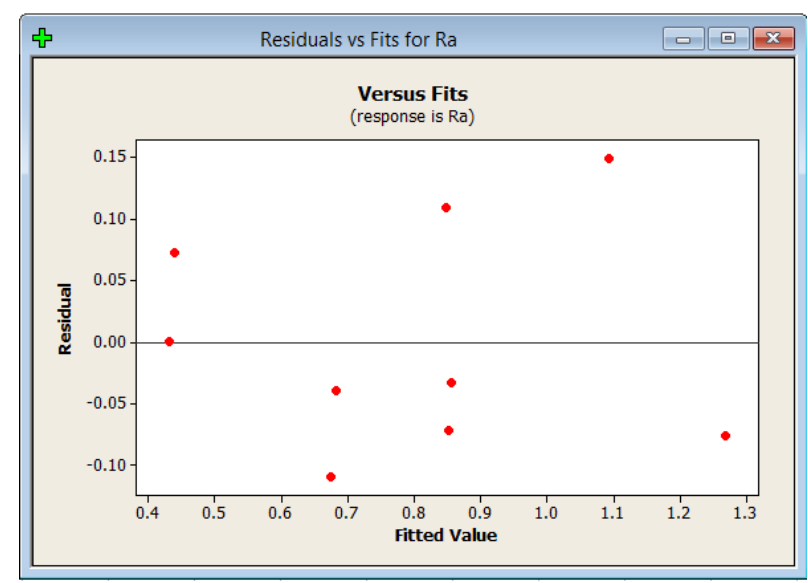

Gambar 3. Plot residual versus fitted values for $\mathrm{Ra}$

Uji asumsi identik pada Gambar 3. Menunjukkan bahwa residual tidak membentuk suatu pola tertentu dan tersebar secara acak disekitar harga nol, sehingga asumsi identik telah terpenuhi. 
Uji asumsi independen

Pengujian asumsi independen dilakukan dengan memakai auto correlation function (ACF). Berdasarkan plot ACF yang ditunjukkan pada Gambar 4, dapat diketahui bahwa tidak ada nilai ACF pada tiap lag yang keluar dari batas interval. Hal ini membuktikan bahwa tidak ada korelasi antar residual, sehingga asumsi independen terpenuhi.

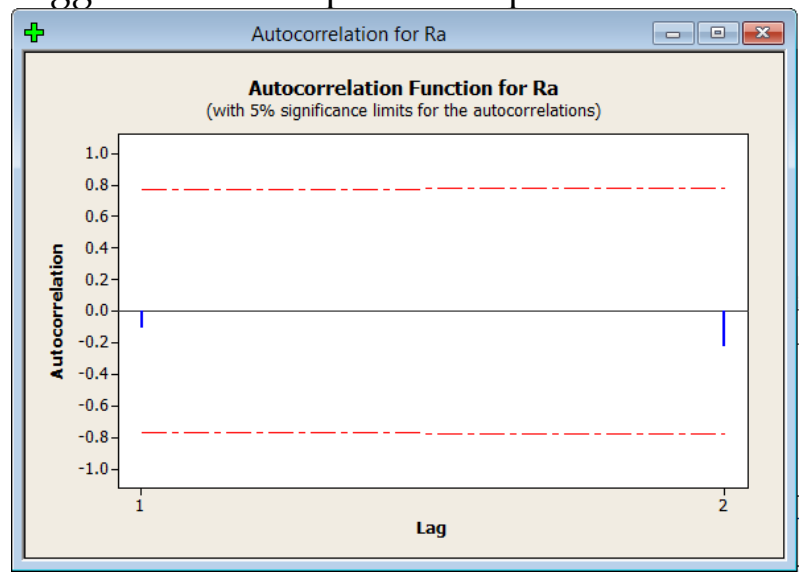

Gambar 4. Plot ACF

Uji Distribusi Normal

Uji distribusi normal dilakukan dengan memakai Kolmogorov-Smirnov. Hipotesis yang digunakan adalah:

$\mathrm{H}_{0}$ : Residual berdistribusi normal

$\mathrm{H}_{1}$ : Residual tidak berdistribusi normal

$\mathrm{H}_{0}$ ditolak jika $\mathrm{p}_{\text {-value }}$ lebih kecil dari 0,05.

Berdasarkan Gambar 4 dapat diperoleh $p_{\text {-value }}$ sebesar $>0,150$, nilai ini lebih besar dari 0,05. Kesimpulan hipotesisnya adalah $\mathrm{H}_{0}$ diterima. Ini berarti residual telah memenuhi syarat berdistribusi normal.

Analisis ANOVA

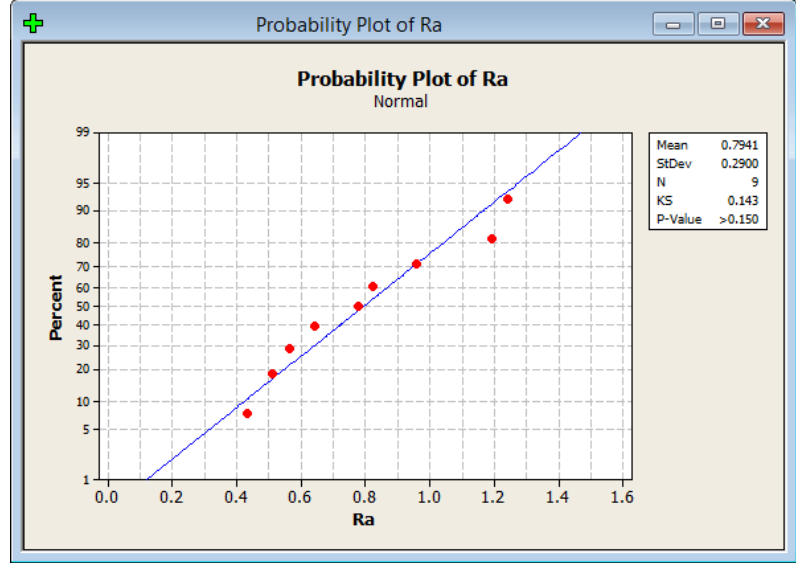

Gambar 5. Uji distribusi normal

Setelah data memenuhi syarat asumsi identik, independen dan berdistribusi normal, kemudian dilakukan analisis ANOVA, untuk mengetahui apakah parameter proses berpengaruh signifikan terhadap respon kekasaran permukaan benda kerja hasil pengefraisan. Setelah dianalisis dengan ANOVA, diperoleh bahwa $F_{\text {value }}$ dari masing-masing variabel independen dibandingkan dengan $\mathrm{F}_{(0,05)}$ dengan ketentuan bahwa jika nilai $F_{\text {value }}<$ $\mathrm{F}_{0,05}$ maka $\mathrm{H}_{0}$ diterima dan jika nilai $F_{\text {value }}>F_{(0,05)}$ maka $\mathrm{H}_{0}$ ditolak (Setyowidodo, Sutanto, Mufarrih, \& Sholehah, 2020). ANOVA untuk kekasaran permukaan ditunjukkan pada Tabel 4 . 
Tabel 4. ANOVA Parameter Proses terhadap Kekasaran Permukaan

\begin{tabular}{lrlllcccc}
\hline Source & DF & Seq SS & Adj SS & Adj MS & F & SS' & P & \% kontribusi \\
\hline N & 2 & 0,26312 & 0,26312 & 0,13156 & 8,13 & 0,23076 & 0,039 & 34,29 \\
Vf & 2 & 0,3451 & 0,3451 & 0,17255 & 10,66 & 0,31274 & 0,025 & 46,47 \\
Error & 4 & 0,06472 & 0,06472 & 0,01618 & & & & 19,23 \\
Total & 8 & 0,67294 & & & & & & 100,00 \\
\hline
\end{tabular}

Level tiap faktor yang berpengaruh terhadap kekasaran permukaan ditunjukkan pada Gambar 6. Berikut.

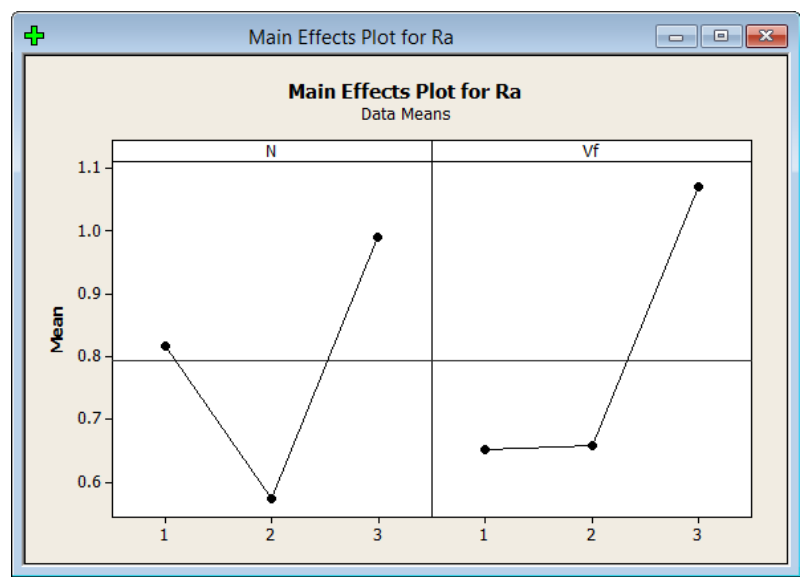

Gambar 6. Main effect plot for Ra

Berdasarkan hasil analisis ANOVA dapat dijelaskan pengaruh parameter proses terhadap respon kekasaran permukaan sebagai berikut:

Pengaruh Kecepatan spindel terhadap kekasaran permukaan

Hipotesis yang digunakan pada uji hipotesis dengan menggunakan distribusi $\mathrm{F}$ adalah sebagai berikut:

$$
\begin{aligned}
& \mathrm{H}_{0}: \mathrm{N}_{1}=\mathrm{N}_{2} \\
& \mathrm{H}_{1}: \mathrm{N}_{1} \neq \mathrm{N}_{2}
\end{aligned}
$$

Kesimpulan: $\mathrm{F}_{\text {hitung }}=8,13>\mathrm{F}(0,05 ; 2 ; 24)=3,4$ maka $\mathrm{H}_{0}$ ditolak, artinya ada pengaruh yang signifikan kecepatan spindel terhadap kekasaran permukaan. Selain itu juga diperoleh P-value sebesar 0,039<0,05, sehingga dapat disimpulkan bahwa parameter proses kecepatan spindel mempunyai pengaruh signifikan terhadap kekasaran permukaan.

Pengaruh Kecepatan pemakanan terhadap kekasaran permukaan

Hipotesis yang digunakan pada uji hipotesis dengan menggunakan distribusi $\mathrm{F}$ adalah sebagai berikut:

$$
\begin{aligned}
& \mathrm{H}_{0}: \mathrm{Vf}_{1}=\mathrm{Vf}_{2} \\
& \mathrm{H}_{1}: \mathrm{Vf}_{1} \neq \mathrm{Vf}_{2}
\end{aligned}
$$

Kesimpulan: $\mathrm{F}_{\text {hitung }}=10,66>\mathrm{F}(0,05 ; 2 ; 24)=3,4$ maka $\mathrm{H}_{0}$ ditolak, artinya ada pengaruh yang signifikan kecepatan pemakanan terhadap kekasaran permukaan. Selain itu juga diperoleh P-value sebesar 0,025 < 0,05, sehingga dapat disimpulkan bahwa parameter proses kecepatan pemakanan berpengaruh signifikan terhadap kekasaran permukaan.

Berdasarkan Tabel 4, parameter-parameter proses yang secara statistik berpengaruh signifikan terhadap respon kekasaran permukaan yaitu kecepatan pemakanan dan kecepatan spindel. Kontribusi terbesar terhadap respon kekasaran permukaan diberikan oleh kecepatan pemakanan, yaitu sebesar $46,47 \%$, diikuti oleh kecepatan spindel yaitu sebesar $34,29 \%$. Hal ini 
sejalan dengan penelitian yang dilakukan Karkalos (Karkalos, Galanis, \& Markopoulos, 2016) tentang prediksi kekasaran permukaan pada proses milling material paduan Ti-6Al-4V ELI. Hasil penelitiannya menunjukkan bahwa faktor yang paling berpengaruh terhadap respon kekasaran permukaan ialah kecepatan pemakanan, kecepatan potong dan kedalaman potong. Kekasaran permukaan yang rendah dapat dicapai dengan kecepatan pemakanan yang rendah dan kecepatan spindel yang tinggi. Hal serupa juga dicapai oleh Kiswanto (Kiswanto, Mandala, Azmi, \& Ko, 2020), yang melakukan penelitian tentang pengaruh parameter pemotongan terhadap kekasaran permukaan pada proses frais kecepatan tinggi. Hasil penelitiannya menunjukkan bahwa kecepatan spindel dan gerak makan sangat berpengaruh signifikan terhadap kekasaran permukaan material paduan Titanium Ti-6Al-4V. Semakin tinggi kecepatan spindel maka akan diperoleh kekasaran permukaan yang makin baik.

\section{KESIMPULAN DAN SARAN} bahwa:

Berdasarkan hasil penelitian serta analisa data yang telah dilakukan, dapat disimpulkan

Ada pengaruh parameter proses kecepatan spindel dan kecepatan pemakanan terhadap respon kekasaran permukaan benda kerja hasil pengefraisan dan terdapat kontribusi parameter-parameter proses pengefraisan dalam mengurangi variasi respon kekasaran permukaan adalah kecepatan pemakanan sebesar $46,47 \%$ dan kecepatan spindel sebesar $34,29 \%$.

\section{UCAPAN TERIMAKASIH}

Terimakasih kami tujukan kepada P2M Politeknik Negeri Malang atas dukungan yang diberikan sehingga penelitian dengan no: 5445/PL2.1/HK/2020 dapat dilaksanakan dengan baik.

\section{DAFTAR RUJUKAN}

Bagno, A., \& Di Bello, C. (2004). Surface treatments and roughness properties of Ti-based biomaterials. Journal of Materials Science: Materials in Medicine. https://doi.org/10.1023/B:JMSM.0000042679.28493.7f

Bruce, 2011. (2013). Analisis Kekasaran Permukaan Dan Getaran Pada Pemesinan Bubut Menggunakan Pahat Putar Modular (Modular Rotary Tools) Untuk Material Titanium 6Al-4V Eli. Journal of Chemical Information and Modeling. https://doi.org/10.1017/CBO9781107415324.004

Davim, J. P. (2011). Machining of hard materials. Machining of Hard Materials. https://doi.org/10.1007/978-1-84996-450-0

Ganguli, S., \& Kapoor, S. G. (2016). Improving the performance of milling of titanium alloys using the atomization-based cutting fluid application system. Journal of Manufacturing Processes. https://doi.org/10.1016/j.jmapro.2016.05.011

Karkalos, N. E., Galanis, N. I., \& Markopoulos, A. P. (2016). Surface roughness prediction for the milling of Ti-6Al-4V ELI alloy with the use of statistical and soft computing techniques. Measurement: Journal of the International Measurement Confederation. https://doi.org/10.1016/j.measurement.2016.04.039 
Kiswanto, G., Mandala, A., Azmi, M., \& Ko, T. J. (2020). The effects of cutting parameters to the surface roughness in high speed cutting of micro-milling titanium alloy ti-6al-4v. Key Engineering Materials, 846 KEM, 133-138. https://doi.org/10.4028/www.scientific.net/KEM.846.133

Mufarrih, A., Istiqlaliyah, H., \& Ilha, M. M. (2019). Optimization of Roundness, MRR and Surface Roughness on Turning Process using Taguchi-GRA. In Journal of Physics: Conference Series. https://doi.org/10.1088/1742-6596/1179/1/012099

Nithyanandam, J., Das, S. L., \& Palanikumar, K. (2015). Inluence of Cutting Parameters in Machining of Titanium Alloy. Indian Journal of Science and Technology, 8(8), 556-562. https://doi.org/10.17485/ijst/2015/v8i/71291

Oshida, Y. (2012). Bioscience and Bioengineering of Titanium Materials: Second Edition. Bioscience and Bioengineering of Titanium Materials: Second Edition. https://doi.org/10.1016/C20110-07805-5

Setyowidodo, I., Sutanto, S., Mufarrih, A., \& Sholehah, I. M. (2020). Exhaust temperature and peltier element optimization of thermoelectric generator output. In IOP Conference Series: Materials Science and Engineering. https://doi.org/10.1088/1757899X/850/1/012007

Shucai, Y., Chunsheng, H., \& Minli, Z. (2019). A prediction model for titanium alloy surface roughness when milling with micro-textured ball-end cutters at different workpiece inclination angles. International Journal of Advanced Manufacturing Technology. https://doi.org/10.1007/s00170-018-2852-6

Soepangkat, B. O. P., Pramujati, B., Effendi, M. K., Norcahyo, R., \& Mufarrih, A. M. (2019). Multi-objective Optimization in Drilling Kevlar Fiber Reinforced Polymer Using Grey Fuzzy Analysis and Backpropagation Neural Network-Genetic Algorithm (BPNN-GA) Approaches. International Journal of Precision Engineering and Manufacturing. https://doi.org/10.1007/s12541-019-00017-z

Tapiero, H., Townsend, D. M., \& Tew, K. D. (2003). Trace elements in human physiology and pathology. Copper. Biomedicine and Pharmacotherapy. https://doi.org/10.1016/S07533322(03)00012-X

Thepsonthi, T., \& Özel, T. (2012). Multi-objective process optimization for micro-end milling of Ti-6Al-4V titanium alloy. International Journal of Advanced Manufacturing Technology. https://doi.org/10.1007/s00170-012-3980-z

Wennerberg, A., \& Albrektsson, T. (2009). Effects of titanium surface topography on bone integration: A systematic review. Clinical Oral Implants Research. https://doi.org/10.1111/j.1600-0501.2009.01775.x 